\title{
Elevated Levels of Both Cardiomyocyte Membrane and Myofibril Damage Markers Predict Adverse Outcomes in Patients With Chronic Heart Failure
}

\author{
Koichi Setsuta, MD; Yoshihiko Seino, MD*; Yasuyuki Kitahara, MD; Masato Arau, MD; \\ Taminori Ohbayashi, MD; Teruo Takano, MD**; Kyoichi Mizuno, MD**
}

\begin{abstract}
Background Recent studies have shown the presence of ongoing myocardial damage in patients with chronic heart failure (CHF) detected by myofibril and membrane damage markers, cardiac troponin $\mathrm{T}(\mathrm{TnT})$ and hearttype fatty acid-binding protein (H-FABP), which identifies patients at increased risk of a future cardiac event (CE: death or rehospitalization because of worsening CHF). There is a difference between TnT and H-FABP in their release kinetics following myocardial damage.

Methods and Results TnT and H-FABP were measured in 103 patients with CHF and in 31 controls. Patients were classified into 4 groups based on detectable $(\geq 0.01 \mathrm{ng} / \mathrm{ml})$ or undetectable TnT (TnT+ or TnT-) and H-FABP $\geq$ or $<4.5 \mathrm{ng} / \mathrm{ml}$ (mean +2 standard deviations in controls) (high-H-FABP or low-H-FABP). Kaplan-Meier analysis showed that the CE-free rate $(n=43)$ was significantly lower in patients with $\mathrm{TnT}+$ and high-H-FABP than in patients in the other 3 groups (patients with TnT+ and low-H-FABP, TnT- and high-H-FABP, and TnT- and low-H-FABP; $\mathrm{p}=0.02, \mathrm{p}=0.001$ and $\mathrm{p}=0.0002$, respectively). In stepwise multivariate Cox proportional hazard analysis, TnT+ $(\mathrm{p}=0.01)$ and high-H-FABP $(\mathrm{p}=0.04)$ were independent predictors of future CE.
\end{abstract}

Conclusions Elevated levels of both TnT and H-FABP predict adverse outcomes in CHF patients. (Circ J 2008; 72: 569-574)

Key Words: Biomarkers; Heart failure; Prognosis

$\mathbf{H}$ eart failure (HF) is a global health problem. Patients with HF have high readmission rates after discharge $^{1}$ and it is therefore important to be able to assess their prognosis to prevent readmission. There are several prognostic indicators of HF. Ventricular remodeling is the major mechanism of progression and is closely related to prognosis 2,3 Cardiomyocyte loss resulting from myocardial damage and fibrosis principally contribute to ventricular remodeling.,5 Recent studies have reported the clinical significance of ongoing myocardial damage in patients with chronic HF (CHF) detected by cardiac troponin $\mathrm{T}(\mathrm{TnT})$ or $\mathrm{I}^{6}$ for identifying patients at increased risk of a subsequent cardiac event (CE) ${ }^{7-12}$ Serum levels of hearttype fatty acid-binding protein (H-FABP), a low-molecular protein that is abundant in the cytosol of cardiomyocytes and is a useful marker of early phase acute myocardial infarction, 13,14 are also increased ${ }^{9,15,16}$ and reflect ongoing myocardial damage ${ }^{17}$ in patients with CHF. However, there is a difference between TnT and H-FABP in their release

(Received June 22, 2007; revised manuscript received November 8 , 2007; accepted November 16, 2007)

Department of Cardiology and Clinical Laboratory, Tokyo Metropolitan Komagome Hospital, Tokyo, *Department of Internal Medicine and Cardiovascular Center, Nippon Medical School Chiba Hokusoh Hospital, Chiba and **Department of Internal Medicine, Nippon Medical School, Tokyo, Japan

Mailing address: Koichi Setsuta, MD, Department of Cardiology and Clinical Laboratory, Tokyo Metropolitan Komagome Hospital, 3-18-22 Honkomagome, Bunkyo-ku, Tokyo 113-8677, Japan. E-mail: setsuta @ cick.jp

All rights are reserved to the Japanese Circulation Society. For permissions, please e-mail: cj@j-circ.or.jp kinetics following myocardial damage and H-FABP measurement compensates for the limitations of TnT in the early phase of acute myocardial infarction. 18 Thus, we reasoned that the combination of both markers would be clinically useful for pathophysiological analysis of ongoing myocardial damage in patients with CHF. We previously reported that both TnT and H-FABP were independent predictors of future $\mathrm{CE}$ in patients with $\mathrm{CHF}$, but there have been no reports concerning the usefulness of combined $\mathrm{TnT}$ and H-FABP measurements in patients with CHF. The purpose of the present study was to elucidate whether the combination of TnT, a marker of myofibril damage, and $\mathrm{H}$ FABP, a marker of membrane damage, can add value to the assessment of the severity and prognosis of CHF.

\section{Methods}

Study Population

The study population consisted of 103 patients with CHF (left ventricular ejection fraction (LVEF) $<50 \%$; 37 women, 66 men; aged $67 \pm 12$ years) who were hospitalized from December 1999 to October 2004, and 31 age- and gendermatched controls (13 women, 18 men; aged $65 \pm 7$ years) visiting the outpatient clinic and who were diagnosed as free of cardiovascular and other disease. The diagnosis of CHF was based on the Framingham criteria ${ }^{19}$ Exclusion criteria were: recent (within 3 months) ischemic heart disease and myocarditis, malignancy, muscle disorders (creatine kinase (CK) $>250 \mathrm{IU} / \mathrm{L}$ in women or $>300 \mathrm{IU} / \mathrm{L}$ in men), renal failure (creatinine $>2.0 \mathrm{mg} / \mathrm{dl}$ ) or active pulmonary, liver, collagen or infectious diseases. The severity of CHF was New York Heart Association (NYHA) class II in 89, class III in 
Table 1 Baseline Characteristics of the 4 Groups of Patients

\begin{tabular}{|c|c|c|c|c|c|}
\hline & $\begin{array}{c}\text { All } \\
(n=103)\end{array}$ & $\begin{array}{c}T n T+ \\
H i g h-H-F A B P \\
(n=25)\end{array}$ & $\begin{array}{c}T n T- \\
\text { High-H-FABP } \\
(n=27)\end{array}$ & $\begin{array}{c}T n T+ \\
\text { Low-H-FABP } \\
(n=10)\end{array}$ & $\begin{array}{c}T n T- \\
\text { Low- } H-F A B P \\
(n=41)\end{array}$ \\
\hline Age, years & $67 \pm 12$ & $68 \pm 11$ & $70 \pm 11^{\ddagger}$ & $68 \pm 10$ & $64 \pm 13$ \\
\hline Men & $66(64 \%)$ & $19(76 \%)$ & $16(59 \%)$ & $5(50 \%)$ & $26(63 \%)$ \\
\hline NYHA class II/III/IV & $89 / 11 / 3$ & $15^{*}+\dot{t}+7 / 7 \pm / 3$ & $25 / 2 / 0$ & $10 / 0 / 0$ & $39 / 2 / 0$ \\
\hline \multicolumn{6}{|l|}{ Etiology } \\
\hline$D C M$ & $41(40 \%)$ & $10(40 \%)$ & $9(33 \%)$ & $2(20 \%)$ & $20(49 \%)$ \\
\hline Hypertensive HD & $26(25 \%)$ & $5(20 \%)$ & $6(22 \%)$ & $3(30 \%)$ & $12(29 \%)$ \\
\hline Previous MI & $28(27 \%)$ & $8(32 \%)$ & $11(41 \%)^{*}$ & $3(30 \%)$ & $6(15 \%)$ \\
\hline Valvular $H D$ & $7(7 \%)$ & $2(8 \%)$ & $1(4 \%)$ & $2(20 \%)$ & $2(5 \%)$ \\
\hline Congenital HD & $1(1 \%)$ & $0(0 \%)$ & $0(0 \%)$ & $0(0 \%)$ & $1(2 \%)$ \\
\hline$C T R, \%$ & $57 \pm 8$ & $60 \pm 9$ & $56 \pm 7$ & $59 \pm 7$ & $57 \pm 8$ \\
\hline $\mathrm{Cr}, \mathrm{mg} / \mathrm{dl}$ & $1.0 \pm 0.3$ & $1.2 \pm 0.4$, & $1.1 \pm 0.4^{t, t}$ & $0.8 \pm 0.1$ & $0.8 \pm 0.2$ \\
\hline$C K, I U / L$ & $75 \pm 61$ & $73 \pm 50$ & $72 \pm 85$ & $74 \pm 64$ & $78 \pm 50$ \\
\hline$C K-M B, I U / L$ & $6 \pm 5$ & $9 \pm 6^{*,+, \#}$ & $5 \pm 5$ & $5 \pm 4$ & $4 \pm 4$ \\
\hline$H-F A B P, n g / m l$ & $5.6 \pm 3.4$ & $9.4 \pm 4.6^{*,+, t}$ & $6.2 \pm 1.3^{\dagger, t}$ & $3.6 \pm 0.5$ & $3.3 \pm 0.8$ \\
\hline$A N P, p g / m l$ & $107 \pm 103$ & $175 \pm 152 *, t, \dot{f}$ & $70 \pm 59$ & $91 \pm 51$ & $93 \pm 80$ \\
\hline$B N P, p g / m l$ & $349 \pm 398$ & $593 \pm 581 *,+\frac{1}{4}$ & $263 \pm 358$ & $316 \pm 248$ & $264 \pm 230$ \\
\hline $\mathrm{NE}, \mathrm{pg} / \mathrm{ml}$ & $593 \pm 392$ & $725 \pm 498$ & $554 \pm 308$ & $452 \pm 587$ & $573 \pm 308$ \\
\hline$L V E F, \%$ & $34 \pm 10$ & $30 \pm 10^{\ddagger}$ & $33 \pm 9$ & $36 \pm 10$ & $36 \pm 11$ \\
\hline
\end{tabular}

${ }^{*} p<0.05$ vs TnT- and high-H-FABP; ${ }^{\dagger} p<0.05$ vs TnT+ and low-H-FABP; ${ }^{\ddagger} p<0.05$ vs TnT- and low-H-FABP.

TnT+, detectable troponin T; TnT-, undetectable troponin T; H-FABP, heart-type fatty acid-binding protein; NYHA, New York Heart Association; DCM, dilated cardiomyopathy; HD, heart disease; MI, myocardial infarction; CTR, cardiothoracic ratio; Cr, creatinine; $C K$, creatine kinase; ANP, A-type natriuretic peptide; BNP, B-type natriuretic peptide; NE, norepinephrine; LVEF, left ventricular ejection fraction.

11, and class IV in 3 patients. The etiology of CHF was dilated cardiomyopathy in 41 patients, previous myocardial infarction in 28, hypertensive heart disease in 26, valvular heart disease in 7, and congenital heart disease in 1 patient. Informed consent was given by all participants.

\section{Measurement of Biochemical Markers}

Blood samples were obtained from the CHF patients when their condition had stabilized (5-20 days after hospitalization). Serum levels of TnT and H-FABP were measured using an enzyme-linked immunosorbent assay (TnT: Elecsys Troponin T, Roche Diagnostics, Mannheim, Germany; detection limit: $0.01 \mathrm{ng} / \mathrm{ml}$; and H-FABP: MARKIT-M; Dainippon-Sumitomo Pharmaceutical Company, Osaka, Japan; detection limit: $1.25 \mathrm{ng} / \mathrm{ml}$ ). Plasma levels of A- and B-type natriuretic peptides (ANP and BNP) (ANP: Shionoria ANP, Shionogi Co Ltd, Osaka, Japan and BNP: Shionoria BNP, Shionogi Co Ltd), norepinephrine (HLC725 CA II, Tosoh Co, Tokyo, Japan) and serum levels of CK (Shikarikid CK, Kanto Medical Co, Inc, Tokyo, Japan) and CK-MB (Shikarikid CK-MB, Kanto Medical) were measured simultaneously. Other clinical parameters included the cardiothoracic ratio calculated from chest radiograph and LVEF evaluated by $99 \mathrm{~m}$ technetium albumin radionuclide ventriculography. Chest radiography and radionuclide ventriculography were performed within 2 weeks of the measurement of TnT and H-FABP.

\section{Classification of Patients}

Patients with CHF were classified into 4 groups: (1) detectable TnT ( $\geq 0.01 \mathrm{ng} / \mathrm{ml} ; \mathrm{TnT}+)$ and H-FABP $\geq 4.5 \mathrm{ng} / \mathrm{ml}$ (mean +2 standard deviations in controls; high-H-FABP), (2) TnT+ and H-FABP $<4.5 \mathrm{ng} / \mathrm{ml}$ (low-H-FABP), (3) undetectable TnT (TnT-) and high-H-FABP, and (4) TnTand low-H-FABP.

\section{Follow-up}

All patients were followed up for $28 \pm 26$ months. The endpoint was death or rehospitalization because of worsening $\mathrm{CHF}$ (ie, CE).

\section{Statistical Analysis}

Results are expressed as mean \pm standard deviation. Comparisons of clinical parameters between the patients with $\mathrm{CHF}$ and the controls were performed using an unpaired t-test. Clinical characteristics among the 3 groups were compared by an analysis of variance with the Fisher post hoc test. TnT detection ratios were compared with the chisquare test. CE-free curves were calculated using the Kaplan-Meier method. The association between gender, TnT+, high-H-FABP, NYHA class, age, creatinine, BNP and norepinephrine $>$ median value and $\mathrm{LVEF}<$ median value and $\mathrm{CE}$ were tested in univariate Cox regression models (NYHA class, creatinine, BNP, norepinephrine and LVEF are established prognostic predictors of CHF). Stepwise multivariate Cox proportional hazard analyses were performed using the same parameters as for the univariate analyses and the same parameters plus the combination of TnT + and high-H-FABP. A p-value $<0.05$ was considered statistically significant.

\section{Results}

There were no significant differences between controls and patients with CHF in age, gender and serum levels of $\mathrm{CK}$ and $\mathrm{CK}-\mathrm{MB}$ at baseline. The TnT detection ratio and H-FABP levels in patients with CHF were higher than in the controls (TnT detection ratio: $35 / 103$ vs $0 / 31, \mathrm{p}=0.0004$, H-FABP: $5.6 \pm 3.4$ vs $2.9 \pm 0.8 \mathrm{ng} / \mathrm{ml}, \mathrm{p}<0.0001)$.

Table 1 shows the clinical characteristics of the patients in the 4 groups. There were no significant differences among them in gender, CK, norepinephrine or cardiothoracic ratio. CK-MB and ANP levels were significantly higher in the group of patients with TnT+ and high-H-FABP than in the other 3 groups. BNP was significantly higher in patients with $\mathrm{TnT}+$ and high-H-FABP than in those with $\mathrm{TnT}+$ and 
Table 2 Medications

\begin{tabular}{lccccc}
\hline \hline & $\begin{array}{c}\text { All } \\
(n=103)\end{array}$ & $\begin{array}{c}\text { TnT+ } \\
\text { High-H-FABP } \\
(n=25)\end{array}$ & $\begin{array}{c}\text { TnT- } \\
\text { High-H-FABP } \\
(n=27)\end{array}$ & $\begin{array}{c}\text { TnT+ } \\
\text { Low-H-FABP } \\
(n=10)\end{array}$ & $\begin{array}{c}\text { TnT- } \\
\text { Low- } H \text {-FABP } \\
(n=41)\end{array}$ \\
\hline Diuretics & $90(87 \%)$ & $24(96 \%)$ & $25(93 \%)$ & $8(80 \%)$ & $33(80 \%)$ \\
Aldosterone blockers & $29(28 \%)$ & $6(24 \%)$ & $6(22 \%)$ & $1(10 \%)$ & $16(39 \%)$ \\
ACEI or ARB & $80(78 \%)$ & $20(80 \%)$ & $21(78 \%)$ & $7(70 \%)$ & $32(78 \%)$ \\
Digitalis & $57(55 \%)$ & $15(60 \%)$ & $12(44 \%)$ & $6(60 \%)$ & $24(59 \%)$ \\
$\beta$-blockers & $30(29 \%)$ & $9(36 \%)$ & $7(26 \%)$ & $3(30 \%)$ & $11(27 \%)$ \\
\hline
\end{tabular}

ACEI, angiotensin-converting enzyme inhibitors; ARB, angiotensin II receptor blockers. Other abbreviations as in Table 1.

A
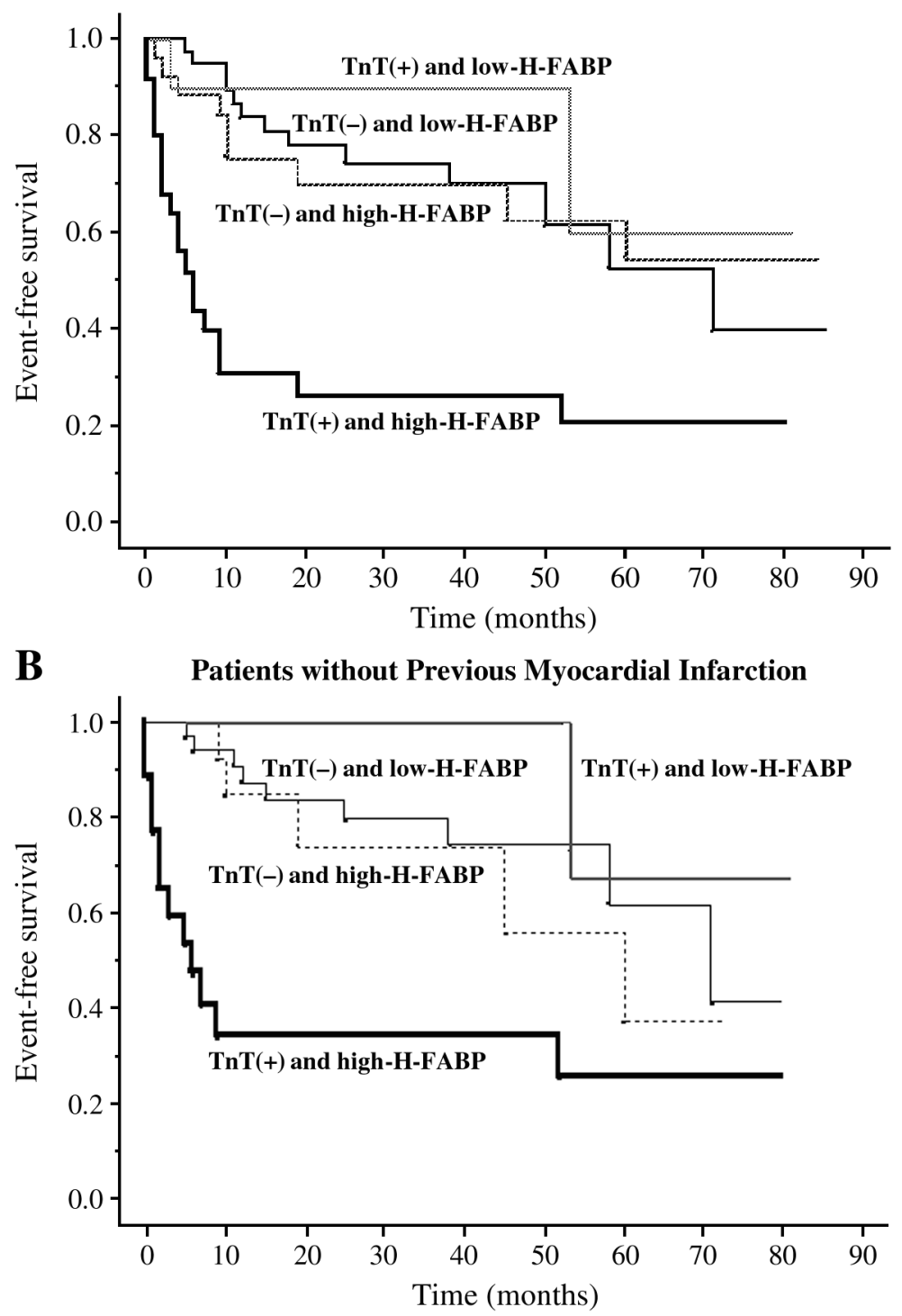

Fig 1. Cardiac event-free survival curves in patients with chronic heart failure (CHF) (A) and CHF patients without previous myocardial infarction (B). TnT(+), detectable troponin T; $\operatorname{TnT}(-)$, undetectable troponin T; $\mathrm{H}-\mathrm{FABP}$, heart-type fatty acid-binding protein.
low-H-FABP, and with TnT- and low-H-FABP. There were no significant differences in the medical treatments of the 4 groups (Table 2).

Kaplan-Meier cumulative CE-free curves in each group are shown in Fig 1A. Over a mean follow-up period of $28 \pm$ 26 months, 15 patients died (13 patients died of worsening HF during hospitalization, but according to electrocardiography and biochemical examinations their deaths were not related to ischemic events; 2 patients had sudden cardiac death associated with worsening HF. In 4 of the 15 patients, the etiology of CHF was a previous myocardial infarction) and 28 patients were rehospitalized because of worsening HF. The cumulative CE-free rate estimated by KaplanMeier curves was significantly lower in patients with TnT+ and high-H-FABP compared with that of the patients in the other 3 groups $(26 \%$ vs $78 \%$ in TnT- and low-H-FABP, $70 \%$ in TnT- and high-H-FABP, and $90 \%$ in TnT+ and low-H-FABP at 2 years, $\mathrm{p}=0.0002,0.001$ and 0.02 , respectively). Fig 1B shows the Kaplan-Meier cumulative CE-free curves in each group of CHF patients without previous myo- 
Table 3 Univariate Analyses and Stepwise Multivariate Analyses

\begin{tabular}{|c|c|c|c|c|c|c|}
\hline & \multicolumn{2}{|c|}{ Univariate analyses } & \multicolumn{4}{|c|}{ Stepwise multivariate analyses } \\
\hline & $H R(95 \% C I)$ & $p$ value & $H R(95 \% C I)$ & $p$ value & $H R(95 \% C I)$ & $p$ value \\
\hline Age $>68$ years & $1.24(0.68-2.25)$ & 0.49 & & 0.60 & & 0.22 \\
\hline Male gender & $1.24(0.70-2.59)$ & 0.37 & & 0.69 & & 0.83 \\
\hline NYHA class III or IV & $2.57(1.23-5.38)$ & 0.01 & & 0.14 & & 0.99 \\
\hline$T n T+$ & $2.57(1.41-4.69)$ & 0.002 & $2.24(1.21-4.14)$ & 0.01 & & 0.83 \\
\hline High-H-FABP & $2.28(1.21-4.29)$ & 0.01 & $1.95(1.02-3.71)$ & 0.04 & & 0.67 \\
\hline$B N P>217.4 \mathrm{pg} / \mathrm{ml}$ & $2.04(1.10-3.76)$ & 0.02 & & 0.17 & & 0.39 \\
\hline$N E>490 \mathrm{pg} / \mathrm{ml}$ & $1.44(0.79-2.64)$ & 0.24 & & 0.05 & & 0.11 \\
\hline LVEF $<34.8 \%$ & $2.03(1.08-3.80)$ & 0.03 & & 0.09 & & 0.10 \\
\hline$C r>0.9 \mathrm{mg} / \mathrm{dl}$ & $1.26(0.68-2.32)$ & 0.46 & & 0.72 & & 0.69 \\
\hline$T n T+$, high-H-FABP & $4.03(2.19-7.41)$ & $<0.0001$ & $-(-)$ & - & $3.82(2.04-7.15)$ & $<0.0001$ \\
\hline
\end{tabular}

HR, hazard ratio; CI, confidence interval. Other abbreviations as in Table 1.

cardial infarction. The cumulative CE-free rate estimated by the Kaplan-Meier curves was also significantly lower in patients with TnT+ and high-H-FABP compared with that of patients in the other 3 groups (34\% vs $84 \%$ in TnT- and low-H-FABP, 74\% in TnT- and high-H-FABP, and 100\% in TnT+ and low-H-FABP at 2 years, $\mathrm{p}=0.002,0.03$ and 0.04 , respectively).

Univariate analyses showed that NYHA class III or IV, TnT+, high-H-FABP, BNP > 217.4 pg/ml, LVEF <34.8\% and TnT+ and high-H-FABP were significant predictors of subsequent CE. Stepwise multivariate Cox proportional hazard analyses revealed that of the 9 variables TnT+ and high-H-FABP were significant and independent predictors of future $\mathrm{CE}$, and only the combination of TnT+ and high$\mathrm{H}-\mathrm{FABP}$ was a significant and independent predictor of $\mathrm{CE}$ among the 9 variables plus the combination of $\mathrm{TnT}+$ and high-H-FABP (Table 3).

\section{Discussion}

\section{Differences in TnT and H-FABP, Myocardial Damage Markers}

TnT is a sensitive and specific marker of minor myocardial damage. It is primarily a component of myofibrils $2^{20}$ thus elevated levels are suggestive of myofibril damage. TnT is released into the circulating blood for several days after the onset of acute myocardial infarction, ${ }^{20}$ which suggests that TnT exists in the circulation for several days following the leakage of cardiomyocyte contents. Therefore, increased TnT levels are indicative of not only current but also recent myofibril damage.

$\mathrm{H}-\mathrm{FABP}$ is abundant in the cytosol and is readily released into the circulation following myocardial membrane damage.21 Its release kinetics are different from those of TnT. In patients with acute myocardial infarction, serum levels of H-FABP return to normal by $24 \mathrm{~h}$ after the onset of myocardial infarction,2 which suggests that H-FABP is rapidly cleared from circulation following leakage from the cytosol. Therefore, H-FABP levels reflect the current extent of myocardial membrane damage.

\section{TnT and H-FABP Levels in Patients With CHF}

The present study showed that elevated levels of both TnT and H-FABP reflected severity and a poor prognosis in patients with CHF. The increased levels of both markers are suggested to be the result of existing myofibril and membrane damage of cardiomyocytes. Studies have shown that leakage of cytosolic enzymes occurs during the early stage of anoxia, but is related to reversible membrane altera- tions; ${ }^{23}$ they also suggest that the degradation of the troponin subunits occurs $4 \mathrm{~h}$ after coronary artery occlusion. ${ }^{24}$ So, although it is possible to recover from cardiomyocyte membrane injury, myofibril damage might be irreversible and it is likely that the increase in both markers identifies continuous irreversible cardiomyocyte damage in CHF patients.

In the present study, H-FABP increased but TnT was not detectable in 27 patients; on the other hand, TnT was detectable without a H-FABP increase in 10 patients. It is assumed that patients with increased H-FABP but undetectable TnT have myocardial membrane damage but no obvious myofibril damage. Thus, myocardial damage in patients with increased H-FABP only is probably less severe than that in patients with increased levels of both TnT and H-FABP. In fact, the present study showed that ANP and BNP levels and the CE rates were significantly higher in patients with increased levels of both markers than in patients with increased H-FABP levels only.

What about myocardial damage in patients with detectable TnT but non-increasing H-FABP? H-FABP is readily released into the circulation following myocardial membrane damage but in cases of acute myocardial infarction the circulating level soon returns to the normal range following leakage of cardiomyocyte contents. ${ }^{2}$ In contrast, the time from the occurrence of myocardial damage to an increased circulating level and that from leakage of cardiomyocyte contents to the return to the normal circulating level is longer for TnT than for H-FABP. Therefore, it is thought that patients with TnT+ but low-H-FABP no longer have current myocardial membrane damage but do have recent myofibril damage. The time-course of ongoing myocardial damage in CHF is still unclear, but our previous report showed that in most patients with $\mathrm{CHF}$, TnT decreased after medical treatment? Del Carlo et al reported that CHF patients with detectable TnT within 4 days of admission, but undetectable TnT 7 days later or undetectable TnT on both days, had lower rates of death, rehospitalization or both than patients with detectable TnT on both days or detectable TnT at the time of the second measurement ${ }^{25}$ Sato et al showed that the CE-free rate was significantly lower in patients with continuous TnT detection than in patients in whom TnT became undetectable or was continuously undetectable? Thus, the prognosis in patients with TnT that becomes undetectable is better than that for patients with continuously detectable TnT. The present study showed that the CE rate and ANP levels were lower in patients with detectable TnT but non-increasing H-FABP than in patients with increased levels of both markers. However, BNP levels in the first group of patients were not significantly 
lower than those seen in patients with increased levels of both markers. The number of patients with TnT+ and low$\mathrm{H}-\mathrm{FABP}$ is small, so there were no significant differences in BNP levels between the 2 groups.

It is suggested that CHF patients with elevated levels of both TnT and H-FABP have more severe myocardial damage than patients who only have elevated TnT or H-FABP and that this reflects a poor prognosis. There are few reports concerning the risk stratification of patients with $\mathrm{CHF}$ using these 2 biomarkers. Ishii et al proposed that measuring the combination of TnT and BNP concentrations at admission may be a highly effective means of risk stratification of patients with $\mathrm{CHF}{ }^{10}$ Niizeki et al reported that the combined measurement of H-FABP and BNP might be a highly reliable evaluation for risk stratification of $\mathrm{CHF}^{26}$ $\mathrm{BNP}$ is an established prognostic predictor in patients with $\mathrm{CHF}$. We assume that the reason why BNP was not an independent prognostic predictor in the present study is the significant correlation between BNP and H-FABP levels $(\mathrm{r}=0.41, \mathrm{p}<0.0001)$. We previously reported a significant correlation between BNP and H-FABP levels, and H-FABP but not BNP was an independent prognostic predictor in patients with CHF? Niizeki et al also showed that H-FABP was the only independent predictor of $\mathrm{CE}$ in patients with CHF by multivariate analysis using 5 variables including BNP27 These results suggest that H-FABP is a new powerful prognostic predictor in $\mathrm{CHF}$ and we believe that based on the results of the present study the combination of TnT and H-FABP levels might be useful for risk stratification of CHF patients.

\section{Study Limitations}

H-FABP is a novel sensitive marker of myocardial damage but its level is significantly influenced by renal function. ${ }^{28}$ In the present study, CHF patients with renal failure (creatinine $>2.0 \mathrm{mg} / \mathrm{dl}$ ) were excluded from the study (maximum creatinine level in CHF patients: $2.0 \mathrm{mg} / \mathrm{dl}$ ). However, the creatinine levels in patients with high-H-FABP were significantly higher than those in patients with low-HFABP. Eighteen of 25 patients $(72 \%)$ with TnT+ and highH-FABP and 21 of 27 (78\%) patients with TnT- and high$\mathrm{H}-\mathrm{FABP}$ had normal renal function (creatinine $\leq 1.2 \mathrm{mg} / \mathrm{dl}$ ). Furthermore, univariate analysis showed that creatinine $>0.9 \mathrm{mg} / \mathrm{dl}$ was not a significant predictor of future CE. Multivariate analysis revealed that $\mathrm{TnT}+$ and high-H-FABP were significant and independent predictors of future $\mathrm{CE}$ among 9 variables including creatinine. Renal dysfunction is an important prognostic predictors in $\mathrm{CHF}^{29,30}$ but the results of this study suggest that the H-FABP level reflects membrane damage rather than the extent of renal dysfunction in $\mathrm{CHF}$. Further investigation is required to determine the relationship between renal dysfunction and the H-FABP level.

\section{References}

1. McAlister FA, Lawson FM, Teo KK, Armstrong PW. A systematic review of randomized trials of disease management programs in heart failure. Am J Med 2001; 110: 378-384.

2. Cohn JN, Ferrari R, Sharpe N, on Behalf of an International Forum on Cardiac Remodeling. Cardiac remodeling: Concepts and clinical implications: A consensus paper from an international forum on cardiac remodeling: On Behalf of an International Forum on Cardiac Remodeling. J Am Coll Cardiol 2000; 35: 569-582.

3. Francis G. Pathophysiology of chronic heart failure. Am J Med 2001; 110(Suppl 7A): 37S-46S.

4. Hein S, Arnon E, Kostin S, Schonburg M, Elsasser A, Polyakova V, et al. Progression from compensated hypertrophy to failure in the pressure-overloaded human heart: Structural deterioration and compensatory mechanisms. Circulation 2003; 25: 984-991.

5. Abbate A, Biondi-Zoccai GG, Bussani R, Dobrina A, Camilot D, Feroce $\mathrm{F}$, et al. Increased myocardial apoptosis in patients with unfavorable left ventricular remodeling and early symptomatic postinfarction heart failure. J Am Coll Cardiol 2003; 41: 753-760.

6. Missov E, Calzolari $\mathrm{CH}$, Pau B. Circulating cardiac troponin I in severe congestive heart failure. Circulation 1997; 96: 2953-2958.

7. Setsuta K, Seino Y, Takahashi N, Ogawa T, Sasaki K, Harada A, et al. Clinical significance of elevated levels of cardiac troponin $\mathrm{T}$ in patients with chronic heart failure. Am J Cardiol 1999; 84: 608-611.

8. Sato Y, Yamada T, Taniguchi R, Nagai K, Makiyama T, Okada H, et al. Persistently increased serum concentrations of cardiac troponin $\mathrm{T}$ in patients with idiopathic dilated cardiomyopathy are predictive of adverse outcomes. Circulation 2001; 103: 369-374.

9. Setsuta K, Seino Y, Ogawa T, Arao M, Miyatake Y, Takano T. Use of cytosolic and myofibril markers in the detection of ongoing myocardial damage in patients with chronic heart failure. Am J Med 2002; 113: $717-722$

10. Ishii J, Nomura M, Nakamura Y, Naruse H, Mori Y, Ishikawa T, et al. Risk stratification using a combination of cardiac troponin $\mathrm{T}$ and brain natriuretic peptide in patients hospitalized for worsening chronic heart failure. Am J Cardiol 2002; 89: 691-695.

11. Horwich TB, Patel J, MacLellan WR, Fonarow GC. Cardiac troponin $\mathrm{I}$ is associated with impaired hemodynamics, progressive left ventricular dysfunction, and increased mortality rates in advanced heart failure. Circulation 2003; 108: 833-838.

12. Perna ER, Macin SM, Canella JP, Augier N, Stival JL, Cialzeta JR, et al. Ongoing myocardial injury in stable severe heart failure: Value of cardiac troponin $\mathrm{T}$ monitoring for high-risk patient identification. Circulation 2004; 110: 2376-2382.

13. Tanaka T, Hirota Y, Sohmiya K, Nishimura S, Kawamura K. Serum and urinary human heart fatty acid-binding protein in acute myocardial infarction. Clin Biochem 1991; 24: 195-200.

14. Ghani F, Wu AH, Graff L, Petry C, Armstrong G, Prigent F, et al. Role of heart-type fatty acid-binding protein in early detection of acute myocardial infarction. Clin Chem 2000; 46: 718-719.

15. Goto T, Takase H, Toriyama T, Sugiura T, Sato K, Ueda R, et al. Circulating concentrations of cardiac proteins indicate the severity of congestive heart failure. Heart 2003; 89: 1303-1307.

16. Arimoto T, Takeishi Y, Shiga R, Fukui A, Tachibana H, Nozaki N, et al. Prognostic value of elevated circulating heart-type fatty acid binding protein in patients with congestive heart failure. J Card Fail 2005; 11: 56-60.

17. Setsuta K, Seino Y, Ogawa T, Ohtsuka T, Seimiya K, Takano T. Ongoing myocardial damage in chronic heart failure is related to activated tumor necrosis factor and Fas/Fas ligand system. Circ J 2004; 68: $747-750$.

18. Seino Y, Ogata K, Takano T, Ishii J, Hishida H, Morita H, et al. Use of a whole blood rapid panel test for heart-type fatty acid-binding protein in patients with acute chest pain: Comparison with rapid troponin T and myoglobin tests. Am J Med 2003; 115: 185-190.

19. McKee PA, Castelli WP, McNamara PM, Kannel WB. The natural history of congestive heart failure: The Framingham study. $N$ Engl J Med 1971; 285: $1441-1446$.

20. Katus HA, Remppis A, Scheffold T, Diederich KW, Kuebler W. Intracellular compartmentation of cardiac troponin $\mathrm{T}$ and its release kinetics in patients with reperfused and nonreperfused myocardial infarction. Am J Cardiol 1991; 67: 1360-1367.

21. Glatz JF, van Bilsen M, Paulussen RJ, Veerkamp JH, van der Vusse GJ, Reneman RS. Release of fatty acid-binding protein from isolated rat heart subjected to ischemia and reperfusion or to calcium paradox. Biochim Biophys Acta 1988; 961: 148-152.

22. Kleine AH, Glatz JF, Van Nieuwenhoven FA, Van der Vusse GJ. Release of heart fatty acid-binding protein into plasma after acute myocardial infarction in man. Mol Cell Biochem 1992; 116: 155-162.

23. Pieper HM, Hutter JF, Spieckermann PG. Relation between enzyme release and metabolic changes in reversible anoxic injury of myocardial cells. Life Sci 1984; 35: 127-134.

24. Toyo-Oka T, Ross J Jr. $\mathrm{Ca}^{2+}$ sensitivity change and troponin loss in cardiac natural actomyosin after coronary occlusion. Am J Physiol 1981; 240: H704-H708.

25. Del Carlo CH, Pereira-Barretto AC, Cassaro-Strunz C, Latorre Mdo $\mathrm{R}$, Ramires JAF. Serial measure of cardiac troponin T levels for prediction of clinical events in decompensated heart failure. J Card Fail 2004; 10: 43-48.

26. Niizeki T, Takeishi Y, Arimoto T, Takahashi T, Okuyama H, Takabatake $\mathrm{N}$, et al. Combination of heart-type fatty acid binding protein and brain natriuretic peptide can reliably risk stratify patients 
hospitalized for chronic heart failure. Circ J 2005; 69: 922-927.

27. Niizeki T, Takeishi Y, Arimoto T, Takabatake N, Nozaki N, Hirono $\mathrm{O}$, et al. Heart-type fatty acid binding protein is more sensitive than troponin $\mathrm{T}$ to detect the ongoing myocardial damage in chronic heart failure patients. J Cardiac Fail 2007; 13: 120-127.

28. Gorski J, Hermens WT, Borawski J, Mysliwiec M, Glatz JF. Increased fatty acid-binding protein concentration in plasma of patients with chronic renal failure. Clin Chem 1997; 43: 193-195.
29. McAlister FA, Ezekowitz J, Tonelli M, Armstrong PW. Renal insufficiency and heart failure: Prognostic and therapeutic implications from a prospective cohort study. Circulation 2004; 109: 1004-1009.

30. Dries DL, Exner DV, Domanski MJ, Greenberg B, Stevenson LW. The prognostic implications of renal insufficiency in asymptomatic and symptomatic patients with left ventricular systolic dysfunction. J Am Coll Cardiol 2000; 35: 681 -689. 